\title{
Epoxidation of Vernonia Oil in Acidic lon Exchange Resin
}

\author{
Tegene Desalegn Zeleke*, Yadessa Melaku Ayana \\ Department of Chemistry, Adama Science and Technology University, Adama, Ethiopia \\ Email address: \\ tegened@yahoo.com (T. D. Zeleke),yadessamelaku2010@gmail.com (Y. M. Ayana) \\ ${ }^{*}$ Corresponding author
}

\section{To cite this article:}

Tegene Desalegn Zeleke, Yadessa Melaku Ayana. Epoxidation of Vernonia Oil in Acidic Ion Exchange Resin. American Journal of Applied Chemistry. Vol. 5, No. 1, 2017, pp. 1-6. doi: 10.11648/j.ajac.20170501.11

Received: January 4, 2017; Accepted: January 17, 2017; Published: February 24, 2017

\begin{abstract}
In this study epoxidized vernonia oil (EVO) was synthesized by the epoxidation of vernonia oil using peroxyformic acid, formed in situ by the reaction of hydrogen peroxide and formic acid in the presence of an acidic ion exchange resin (Amberlite IR-120 hydrogen form) as the catalyst. This method of epoxidation has resulted in product with about $78 \%$ conversion. Acid exchange resin catalyzed epoxidation reactions are found to be promising in minimizing oxirane ring opening.
\end{abstract}

Keywords: Vegetable Oils, Vernonia Oil, Epoxidation

\section{Introduction}

Vegetable oils represent one of the cheapest and most abundant biological feedstock available in large quantities, and their use as starting materials offers numerous advantages, such as low toxicity and inherent biodegradability. They are primarily water insoluble, hydrophobic substances that are made up of one mole of glycerin and three moles of fatty acids, so called triglycerides. The triglyceride structures of vegetable oils such as soybean oil, canola oil, rapeseed oil, sunflower oil, peanut oil, castor oil, palm oil, linseed oil etc., have different functionalities, such as double bond, allylic carbons and ester groups which are potential sites for chemical modification [1].

A broad variety of structurally different and 'unusual' fatty acids occur in the seed oils of plant species, with outstanding potential as feedstock for industry. They include unusual monounsaturated fatty acids, medium, short, or very-longchain fatty acids, fatty acids with additional functional groups such as epoxy and hydroxy groups, or fatty acids with conjugated double bonds [2].

The derivatization of oil-based fatty compounds has recently made significant progress. Chemical modification of fatty compounds is a key route to obtaining useful products from renewable resources [3]. Oleochemical industries have mainly focused on the carboxylic functionality of fatty acids; producing oleochemicals such as free fatty acids, methyl esters, fatty alcohols, and fatty amines, with glycerol as a byproduct. Modern synthesis methods have been recently applied extensively to fatty compounds for the selective modification of the alkyl chain [3].

In this regard, epoxidation of fatty acids has achieved significant attention. Epoxidation is the process of formation of an oxirane (epoxy) group, i.e., cyclic ether in which the oxygen atom is contained in a three membered ring, by the reaction of peroxyacids (peracids) and olefinic double bonds. It is one of the most important and useful modifications using the double bonds of unsaturated fatty compounds, since epoxides are reactive intermediates that readily generate new functional groups [4]. Owing to the high reactivity of the oxirane ring, epoxides can find application as raw materials for preparation of a variety of chemicals, such as alcohols, glycols, alkanolamines, carbonyl compounds, and polymers like polyesters, polyurethanes, and epoxy resins [5].

Epoxidized oils, currently manufactured from animal fats or vegetable oils treated with peracetic acid or from petrochemicals, are widely used in oleochemical industry as plasticizers and stabilizers for thermoplastic products (e.g. PVC), in reformulation of oil based paints, in cosmetics, and for pharmaceutical applications [7]. Oils rich in epoxy fatty acids are useful in the paint industry to reduce emissions of 
volatile organic compounds that produce smog as a result of using petroleum-based (alkyd-resin) paints [8].

Seeds from crops, such as soybeans and linseed, are currently used as major source of unsaturated oils, which are precursors to epoxidized oils [9]. However, the chemical epoxidation process is expensive as well as environmentally damaging. Extensive search to identify plants not competing with existing crops as new sources of industrial raw materials were carried out by the United States Department of Agriculture in the 1950s [10]. Among the many species examined, Vernonia galamensis native to East Africa received increasing attention due to the high concentration of naturally epoxidized oil in its seed which could beused asa potential substitute for currently used epoxy oils [11].

The seeds of Vernonia galamensis are the source of oil which is rich in the unusual fatty acid vernolic acid, cis-12, 13-epoxy-cis-9-octadecenoic acid [10]. It is the epoxy functionality in vernonia oil that makes it unique in comparison to other vegetable oils such as coconut, palm kernel, soybean, sunflower, etc., none of which contain the epoxy functionality.

The potential of Vernonia galamensis as a seed source of oil with inherent usefulness because of its oxirane content has been considered recently from both botanical and chemical viewpoints [12]. The vernolic (76\%), oleic (4\%) and linoleic (13\%) acid levels in Vernonia galamensis oil represent additional epoxidizable unsaturation, so that fully epoxidized VO could have an oxirane value near $10 \%$ [13].

There are several methods for producing epoxides from vegetable oils, fatty acids and methyl esters. These includes epoxidation with percarboxylic acid generated in situ in the presence of acids or enzymes as catalysts [14], epoxidation with organic and inorganic oxidants such as potassium peroxomonosulphate, meta-chloroperoxybenzoic acid and ethyl methydioxirane $[15,16]$, epoxidation with halohydrins for the epoxidation of olefins with electron-deficient double bonds and epoxidation with molecular oxygen [17]. From process, environmental safety and efficiency point of view epoxidation of vegetable oils in one step, i.e., with peroxy acid generated in situ from carboxylic acid (formic/acetic acid) with hydrogen peroxide in the presence of acid catalyst is widely used on an industrial scale. However, the use of a mineral acid as catalyst in epoxidation is inefficient because of problems associated with separation of the catalyst from the reaction product. The process can be made competitive with the use of ion-exchange catalyst instead of traditional homogeneous one in epoxidation of unsaturated compounds [18].

The aim of this study was to synthesize and characterize epoxidized of vernonia oil using peroxyformic acid, formed in situ by the reaction of hydrogen peroxide and formic acid in the presence of an acidic ion exchange resin (Amberlite IR-120 hydrogen form) as the catalyst.

\section{Materials and Methods}

\subsection{Materials}

Vernonia oil was extracted from Vernonia galamensis seed obtained from Adet Agricultural Research Centre, Bahr Dar area. Once the oil is extracted using organic solvents such as n-hexane, purification to remove free fatty acids was carried out using standard procedures [19] and characterized with different techniques. Analytical grade hydrogen peroxide, formic acid in acidic ion exchange resin (Amberlite IR-120 hydrogen form) were purchased from Sigma Aldrich Chemical Company.

\subsection{Instrumentation}

${ }^{1} \mathrm{H}$ NMR and ${ }^{13} \mathrm{C}$ NMR spectra were recorded on a 400 $\mathrm{MHz}$ Bruker 400 Ultra-Shield spectrometer. Chemical shifts $(\delta)$ are reported in parts per million ( $\mathrm{ppm}$ ) with reference to residual traces in the commercial deuterated solvent of protonated dimethyl sulfoxide $\left(\delta_{\mathrm{H}} 2.54\right)$ and $\left(\mathrm{CD}_{3}\right)_{2} \mathrm{SO}\left(\delta_{\mathrm{C}}\right.$ 40.45) at ambient temperature. Fourier Transform Infrared Spectroscopy analysis was performed on a Nicolet model Protégé 460 Magna IR spectrometer. The analysis of the vernonia oil and epoxidized vernonia oil was carried out with analytical grade $\mathrm{KBr}$ pellets using the transmission mode. All the spectra were recorded with $4 \mathrm{~cm}^{-1}$ resolution over 100 scans.

\subsection{Experimental Procedures}

Epoxidized vernonia oil (EVO) was produced by the epoxidation of vernonia oil using peroxyformic acid, formed in situ by the reaction of hydrogen peroxide and formic acid in the presence of an acidic ion exchange resin (Amberlite IR-120 hydrogen form) as the catalyst. The Amberlite IR$120 \mathrm{H}$ catalyst is a copolymer based on styrene (98 wt. \%) cross linked by divinylbenzene (2 wt \%).

A solution of vernonia oil $(0.67 \mathrm{~mol})$, formic acid $(0.67$ mol) and Amberlite IR-120 (15 wt \%) were added to a threenecked round bottom flask equipped with a mechanical stirrer and thermometer. The reactor contents were mixed for five minutes followed by drop wise addition of hydrogen peroxide $(35 \%)$ for one hour. The reaction was then performed over a period of seven hours at $110 \mathrm{rpm}$ and $75{ }^{\circ} \mathrm{C}$. On completion of the reaction the solution was washed with water three times (cool, hot, cool) to remove the residual peroxyacetic acid and then filtered to remove the catalyst. The resulting product was characterized.

\section{Results and Discussion}

\section{1. ${ }^{1} \mathrm{H}$ and ${ }^{13} \mathrm{C}$ NMR Analysis}

The characterization of the epoxidized vernonia oil was carried out using ${ }^{1} \mathrm{H}$ and ${ }^{13} \mathrm{C}$ NMR spectroscopy. 


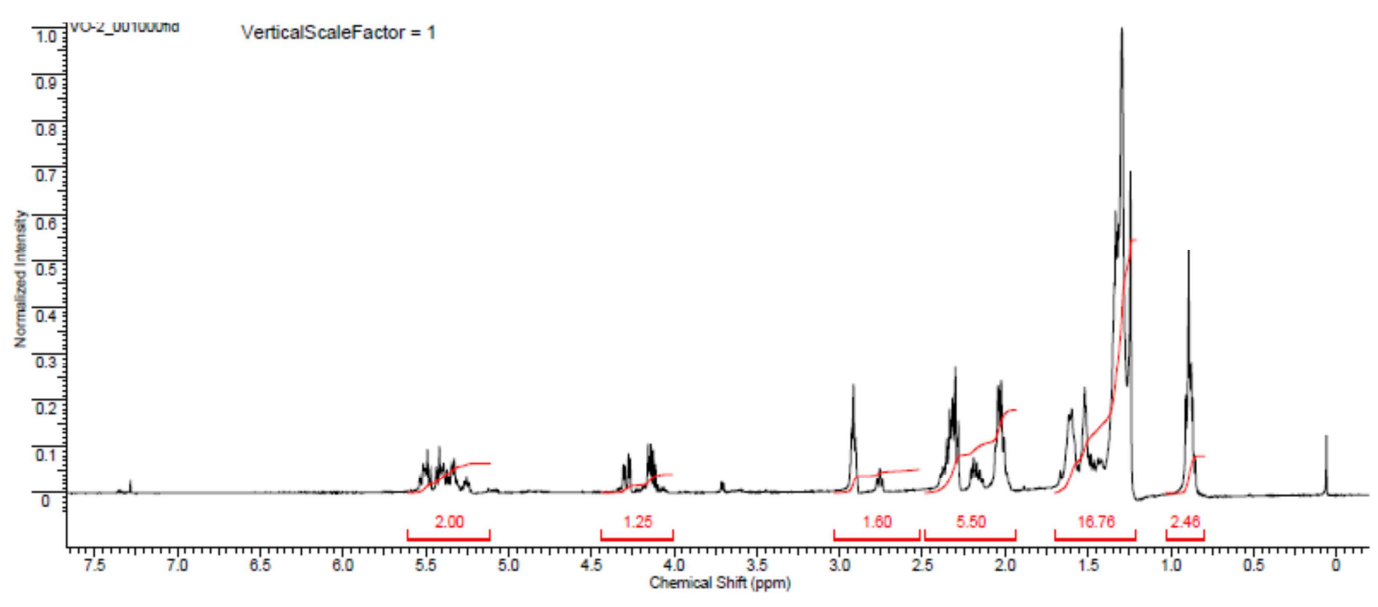

Figure 1. ${ }^{1}$ H NMR spectrum of vernonia oil (before epoxidation).

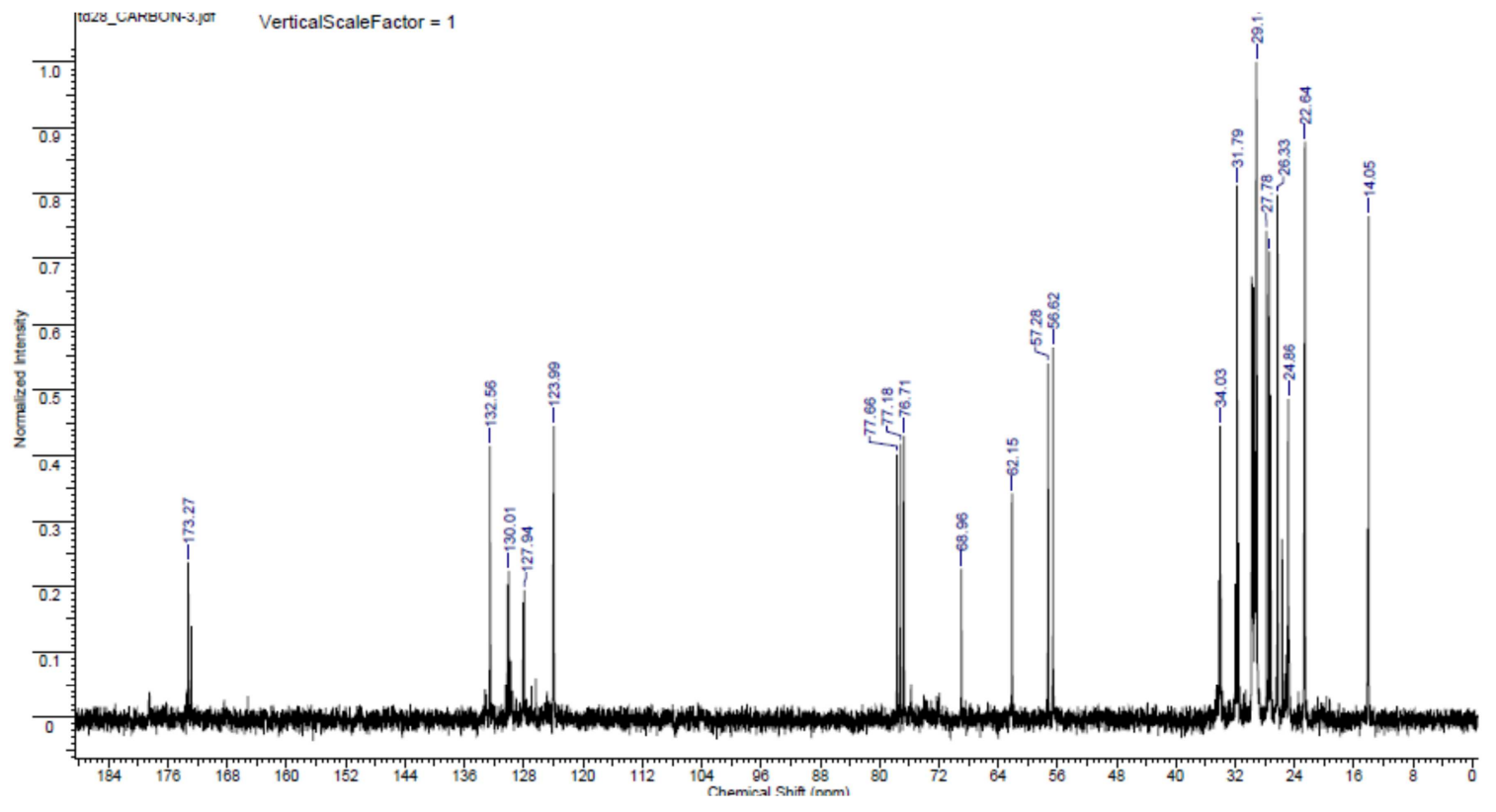

Figure 2. ${ }^{13}$ C NMR spectrum of vernonia oil (before epoxidation).

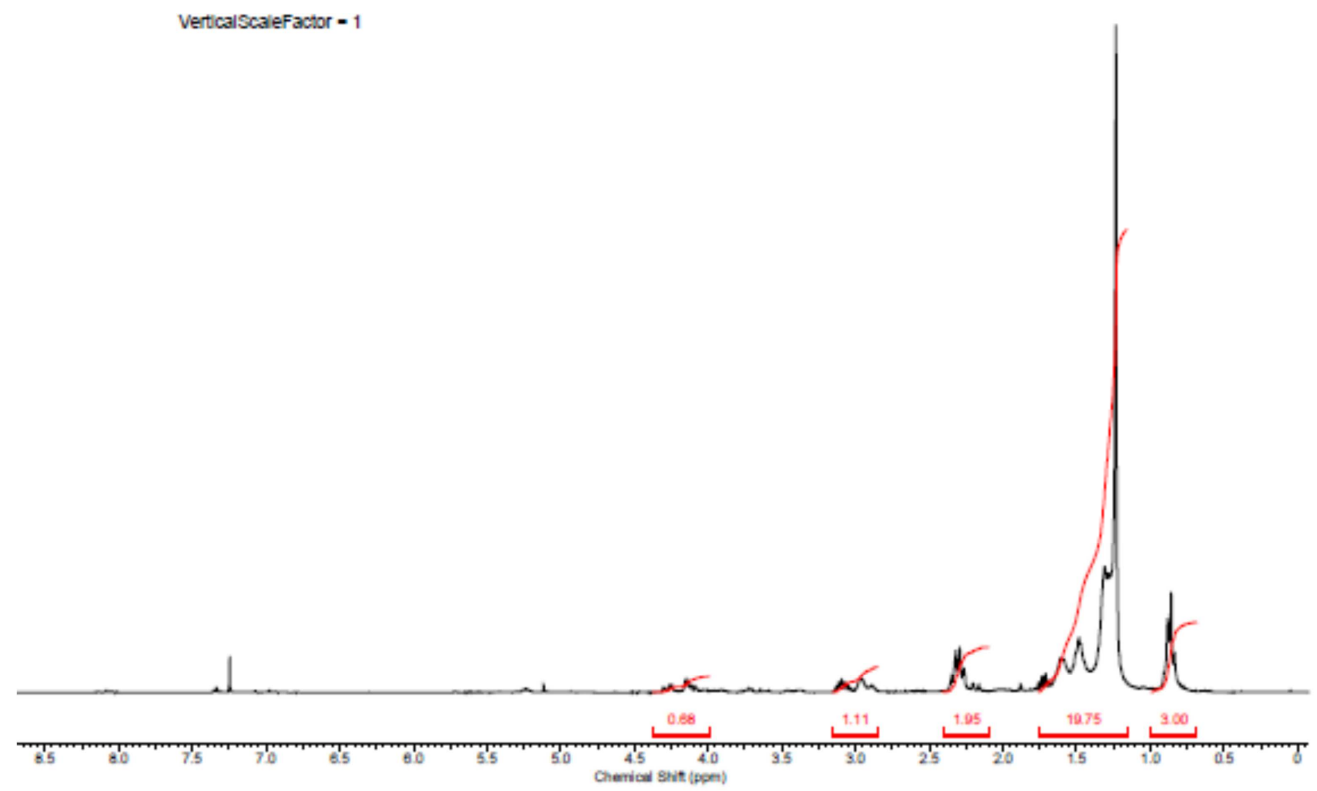

Figure 3. ${ }^{1} H$ NMR spectrum of epoxidized vernonia oil. 


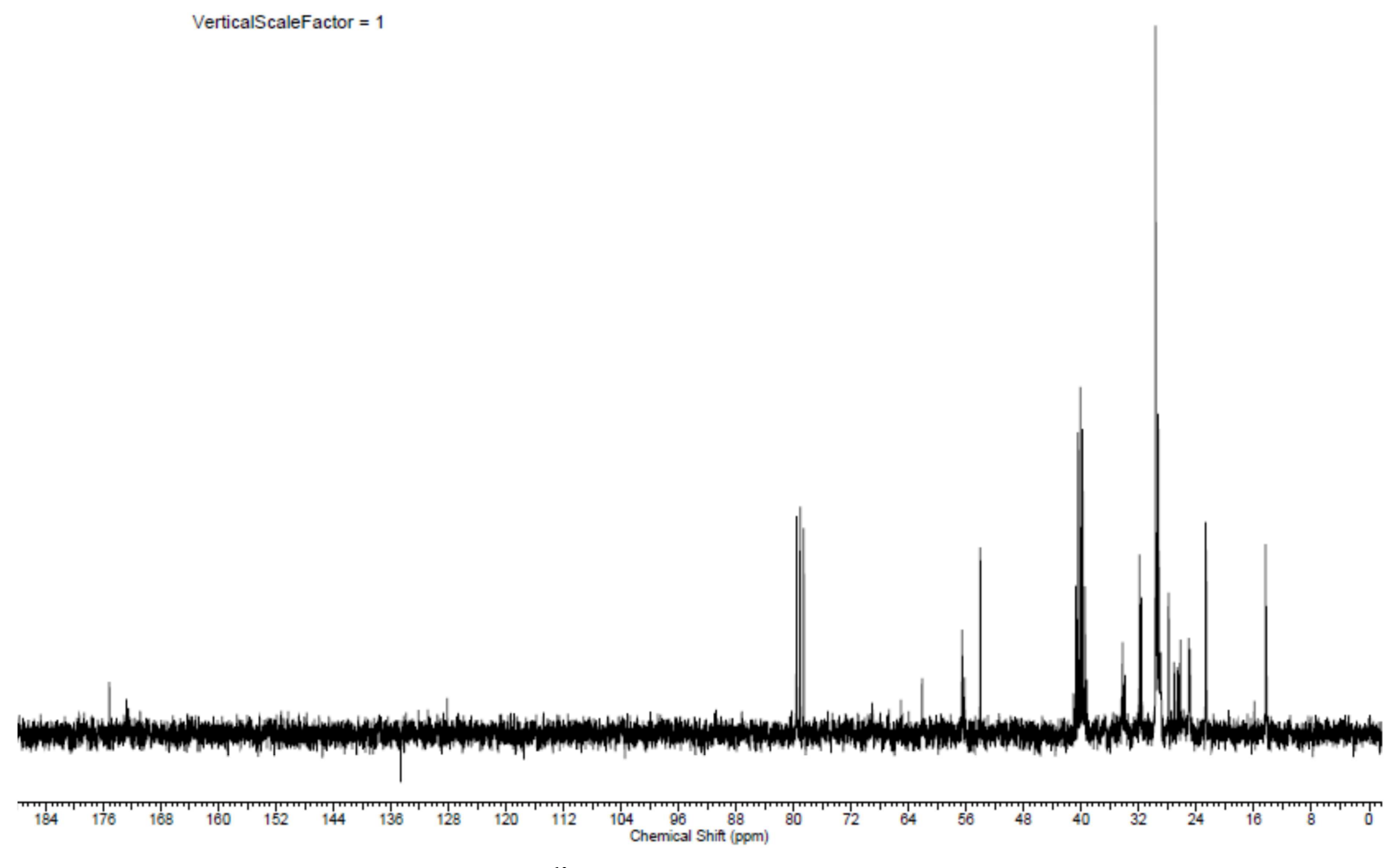

Figure 4. ${ }^{13}$ NMR spectrum of epoxidized vernonia oil.

The ${ }^{1} \mathrm{H}$ NMR data of the epoxidized vernonia oil (Figure 3) shows the presence of secondary and primary glyceral proton at $\delta 5.10-5.20$ and 4.10-4.30, respectively. The proton signal centered at $\delta 3.00$ is evident for the presence of epoxy protons. This is further substantiated by the disappearance of the olefinic proton signals in the region between $\delta 5.34-5.43$. The broad intense signal observed in the region $\delta 1.26-1.63$ is due to the presence of many methylene groups. Furthermore, the proton signal at $\delta 0.89$ is characteristics of terminal methyl groups.

The ${ }^{13} \mathrm{C}$ NMR data (Figure 4) also indicated the presence of the vernolyl carbonyl carbon $(\mathrm{O}=\mathrm{C})$ at $\delta 173.06$, glyceral
(CH) at $\delta$ 68.95, and glyceral $\left(\mathrm{CH}_{2}\right)$ at $\delta$ 62.04-64.99, methylene carbons $\left(\mathrm{CH}_{2}\right) \mathrm{n}$ at $\delta 22.64$ - 34.03, and methyl carbon $\left(\mathrm{CH}_{3}\right)$ at $\delta$ 14.06. On inspection of the ${ }^{13} \mathrm{C}-\mathrm{NMR}$ spectrum of vernonia oil (Figure 2), there are diagnostic signals in the region between $\delta 120-130$ accounted to olefinic carbons. These signals were not detected in the epoxidized vernonia oil (Figure 4) which justifies the disappearance of the double bonds and formation of epoxides. This is further supported by the observed increase in the intensity of the epoxy carbon (Figure 5). Furthermore, the triglyceride structure remained intact after epoxidation.

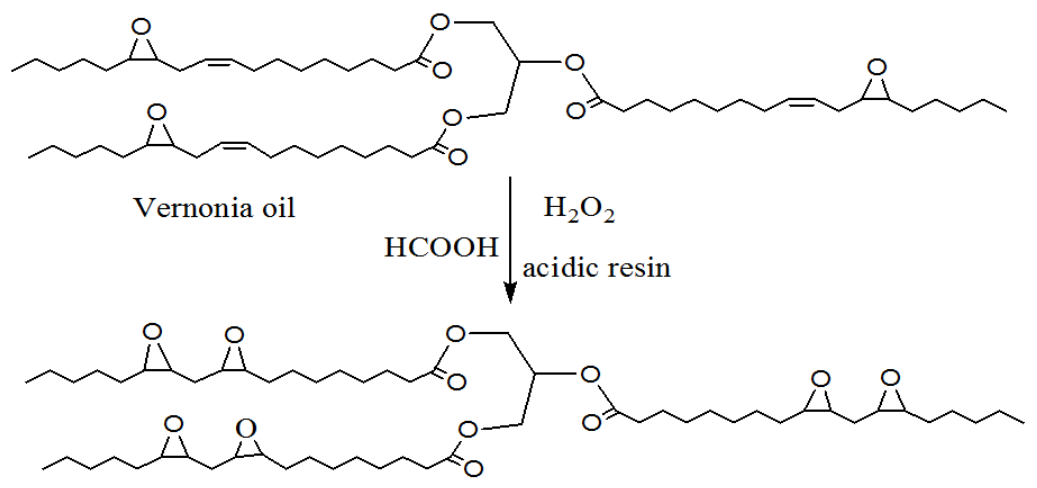

Epoxidized vernonia oil

Figure 5. Epoxidation of vernonia oil using acidic ion exchange resin.

This method of epoxidation has resulted in product with about $78 \%$ conversion. Acid exchange resin catalyzed epoxidation reactions are found to be promising in minimizing oxirane ring opening [20]. The resulting epoxidized vernonia oil is a promising intermediate for synthesis of bio-lubricants. The epoxide, or oxirane, group can be easily functionalized for production of lubricant base stocks from acid-catalyzed oxirane ring-opening reactions followed by esterification of hydroxyl groups [21]. 


\subsection{FTIR Spectrum Analysis}

For vernonia oil the characteristic peaks at 3008,1650 and $723 \mathrm{~cm}^{-1}$ are attributed to the stretching vibration of the double bonds: $=\mathrm{C}-\mathrm{H}, \quad \mathrm{C}=\mathrm{C}$, cis- $\mathrm{CH}=\mathrm{CH}$, respectively. Hernandez-Lopez et al. reported the diminution of peak, $\mathrm{C}=\mathrm{C}-\mathrm{H}$ stretching at $3008 \mathrm{~cm}-1$ after epoxidation reaction, which supports our study where almost complete disappearance of double bonds band at $3008 \mathrm{~cm}-1$ at $75^{\circ} \mathrm{C}$ after $7 \mathrm{~h}$ was observed [22]. This confirms that almost all the $\mathrm{C}=\mathrm{C}-\mathrm{H}$ had taken part in the epoxidation reaction. Also, there is decrease in the intensity of the other important unsaturated bond signals in comparison with the unreacted oil, giving reliable support of its chemical transformation to an oxirane ring.

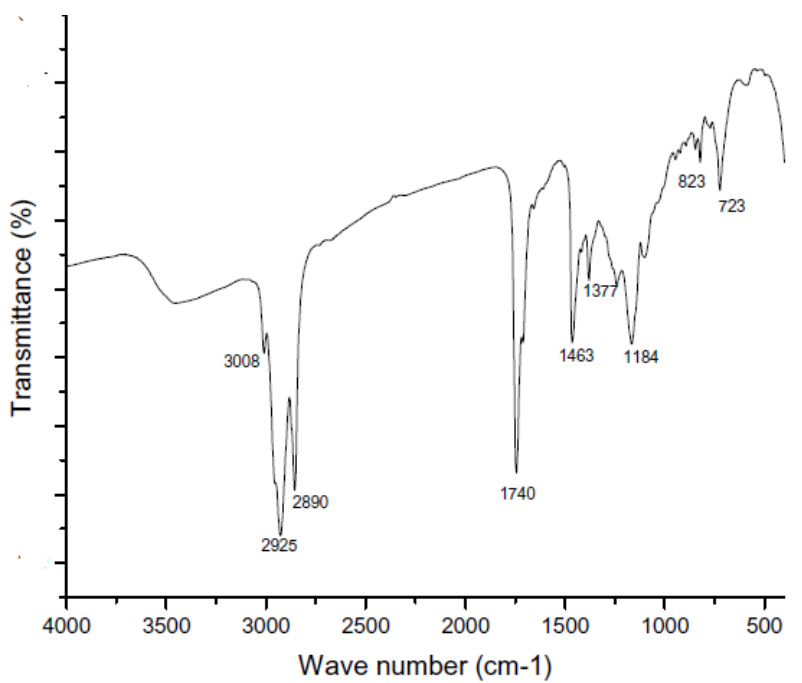

Figure 6. FTIR spectrum of vernonia oil.

The presence of new peaks in the FTIR spectrum of EVO at $820-843 \mathrm{~cm}^{-1}$, attributed to the epoxy group, confirmed the success of the epoxidation reaction of VO. Vleck and Petrovic [23] reported the presence of epoxy groups at 822 $833 \mathrm{~cm}^{-1}$, which agrees well with this study. The other new peak at the $3449 \mathrm{~cm}^{-1}$ was attributed to the hydroxyl functional group, derived from the epoxy functional group via partial epoxy ring opening reaction. The intensity of this band indicates the extent of hydrolysis of epoxidized vernonia oil (EVO). The epoxy ring opening reaction could occur either by acid catalysis in the presence of water associated with aqueous solution of $\mathrm{H}_{2} \mathrm{O}_{2}$ used [24]. The hydrolysis of the ester groups during epoxidation reaction in oils is the main side reaction. In the case of hydrolysis, a carboxylic acid functional group is formed and this carbonyl group will appear near but differentiable of the ester carbonyl stretching $\mathrm{C}=\mathrm{O}$ in the glyceride moiety at $1737 \mathrm{~cm}^{-1}$. However; in the course of the epoxidation reaction carried out in our study, no evidence of the carbonyl from carboxylic acid group signal was observed [25].

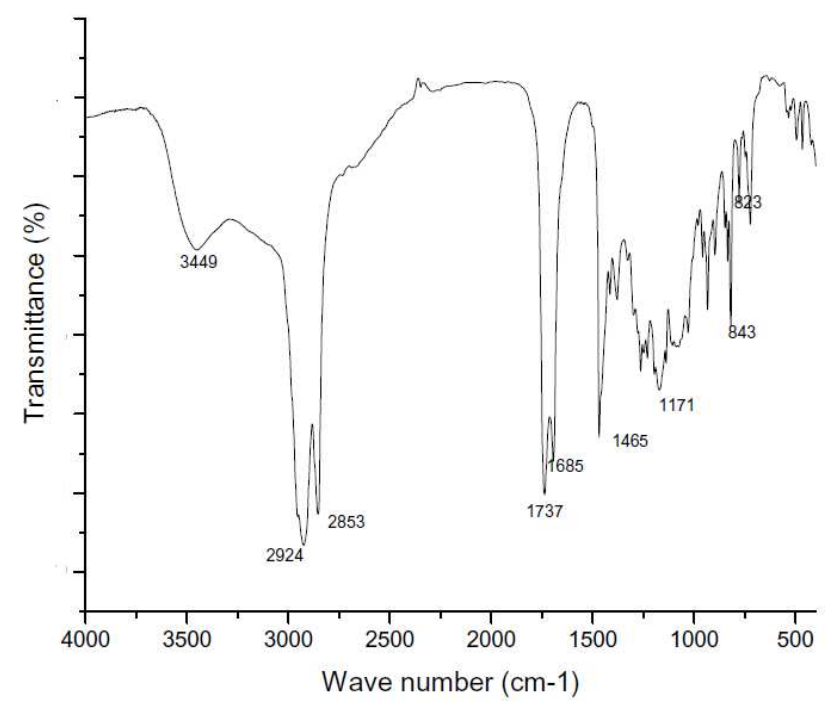

Figure 7. FTIR spectrum of epoxidized vernonia oil.

\section{Conclusions}

In conclusion, epoxidation of vernonia oil occurs in $78 \%$ yield using peroxyformic acid, formed in situ by the reaction of hydrogen peroxide and formic acid in the presence of an acidic ion exchange resin (Amberlite IR-120 hydrogen form) as the catalyst. The resulting epoxidized vernonia oil is a promising intermediate for synthesis of bio-lubricants. Characterization of the epoxidized product was done employing ${ }^{1} \mathrm{H}$ and ${ }^{13} \mathrm{C}$-NMR spectroscopy.

\section{Acknowledgements}

The authors would like to thank Adama Science and Technology University for funding.

\section{References}

[1] Guner, F. S., Yagci, Y., Erciyes, A. T., 2006. Polymers from triglyceride oils. Prog. Polym. Sci. 31, 633-670.

[2] Dyer, J. M., Stymne, S., Green, A. G., Carlsson, A. S., 2008. High-value oils from plants. The Plant Journal, 54, 640-65.

[3] Gunstone, F. D., 2001. Basic Oleochemicals, Oleochemical Products and New Industrial Oils. In: Oleochemical Manufacture and Applications; Gunstone F. D., Hamilton R. J. (eds). Sheffield Academic Press: Sheffield.

[4] Wang, X., Zhang, H., Wang, Z., Jiang, B., 1997. In situ epoxidation of ethylene propylene diene rubber by performic acid. Polymer, 38, 5407-5410.

[5] Dinda, S., Patwardhan, A. V., Goud, V. V., Pradhan, N. C., 2008. Epoxidation of cottonseed oil by aqueous hydrogen peroxide catalyzed by liquid inorganic acids. Bioresource Technol. 3737-3744.

[6] Michael, A. R., Jurgen, O. M., Ulrich, S. S., 2007. Plant oil renewable resources as green alternatives in polymer sciences. Chem. Soc. Rev, 36, 1788-1802. 
[7] Bhardwaj, H. L., Hamama, A. A., Dierig, D. A., 2007. Fatty Acids in Vernonia Produced in the Mid-Atlantic Region of the United States., J Amer Oil Chem Soc, 84: 393-397.

[8] Carvalho, M. G., Patricia, M. C., Abreu, S., Heber, S., 1999. Flavanones from Vernonia diffusa. J. Braz. Chem. Soc., 10, 163

[9] Carlson, K. D, Chang, S. P., 1985. Chemical epoxidation of natural unsaturated epoxy seed oil from vernonia galamensis and a look at epoxy oil markets. J. Am. Oil Chem. Soc., 62, 934-939.

[10] Perdue, R. E. 1988. Systematic botany in the development of Vernonia galamensis as a new industrial oilseed crop for the semi-arid tropics. Symb. Bot. Ups, 28, 125-135.

[11] Baye, T., and Becker, H. C., 2005. Exploration of vernonia galamensis in Ethiopia, and variation in fatty acid composition of seed oil. Genetic Resources and Crop Evolution, 52, 805811 .

[12] Perdue, R. E. Jr., Carlson, K. D., Gilbert, M. G., 1986. Vernonia galamensis, potential new crop source of epoxy fatty acid. Economic botany 40, 54-68.

[13] Carlson, K. D, Chang, S. P., 1985. Chemical epoxidation of natural unsaturated epoxy seed oil from vernonia galamensis and a look at epoxy oil markets. J. Am. Oil Chem. Soc., 62, 934-939.

[14] Okieimen, F. E, Pavithran, C., Bakare, I. O., 2005. Epoxidation and hydroxylation of rubber seed oil: one-pot multi step reactions. Euro. J. Lipid Sci. \& Tech, 107, 864-870.

[15] Carlson, K. D., Kleiman, R., and Bagby, M. O., 1994. Epoxidation of Lesquerella and Limnan- thes (Meadowfoam) Oils. J. Am. Oil Chem. Soc., 71, 175-182.

[16] Marcel, S. F., Lei, K. J. and Mohammad, K. P., 1998. Epoxidation reactions of unsaturated fatty esters with peroxomonosulphate. Lipids, 33, 633-637.

[17] Patwardhan, A. V., Goud, V. V., Pradhan, N. C., 2006. Epoxidation of Karanja (Pongamiaglabra) Oil by $\mathrm{H}_{2} \mathrm{O}_{2} . J . A m$. Oil Chem. Soc., 83, 247-252.

[18] Gurbanov, M. S., and Mamedov, B. A., 2009. Epoxidation of Flax Oil with Hydrogen Peroxide in a Conjugate System in the presence of Acetic Acid and Chlorinated Cation Exchanger KU-2×8 as Catalyst. Russian J. App. Chem.,, 82, 1483-1487.

[19] Ayorinde, F. O., Butler B. D., Clayton, M. T., 1990. Vernonia galamensis: A rich source of epoxy acid. J. Am. Oil Chem. Soc. 67, 844 .

[20] Badran, B. M., El-Mehelmy, F. M., Ghanem, N. A, J. 1976. Oil Colour Chem. Assoc., 59 (8) 291

[21] Goheen, S. M., Wool, R. P., 1991. Degradation of polyethylene starch blends in soil. J. Appl. Polym. Sci., 42, 2691-2701.

[22] Hernandez-Lopez, S., Campo-Lopez, E. M., SanchezMendieta, V., Urena-Nunez, F. and Vigueras- Santiago, E., 2006. Gamma Irradiation on Acrylated-Expoxidized Soybean Oil: Polymerization and Characterization. Adv. In Tech. of Mat. and Mat. Proc. J., 8, 220-225.

[23] Vlcek, T., Petrovic, Z. S., 2006. Optimizationof the chemoenzymatic epoxidation of soybean oil. J. Am. Oil Chem. Soc., 83, 247-252.

[24] Pares, X. P. X., Bonnet, C., and Morin, O., 1999. Synthesis of New Derivatives from Vegetable Oil Methyl Esters via Epoxidation and Oxirane Opening, in Recent Developments in the Synthesis of Fatty Acid Derivative (Knothe, G. and Derksen, J. T. P., Eds.) AOCS Press, Champaign, IL, 141-156.

[25] Lopez-Tellez, G., Vigueras-Santiago, E., Hernandez-Lopez, S., 2009. Characterization of epoxidized linseed oil at different percentage. Surface and Emptiness, 22, 5-10. 